\title{
Person-family centered transition planning: Improving post-school outcomes to culturally diverse youth and families
}

\author{
Edwin O. Achola ${ }^{\mathrm{a}, *}$ and Gary Greene ${ }^{\mathrm{b}}$ \\ ${ }^{a}$ California State University, Long Beach, Cypress, CA, USA \\ ${ }^{\mathrm{b}}$ California State University, Long Beach, Laguna Beach, CA, USA
}

Revised/Accepted April 2015

\begin{abstract}
.
BACKGROUND: The persistent patterns of unsatisfactory transition experiences and adult outcomes of culturally and linguistically diverse (CLD) youth with disabilities are well documented in existing transition literature. The consequences of these circumstances for this unique population of individuals with disabilities are long term and far reaching, both individually and collectively. Unfortunately, despite many years of transition outcomes research, there is a dearth of literature on effective empirically-based culturally reciprocal transition practices.

OBJECTIVE: In this conceptual article, we provide a framework for thinking about how to best plan for and facilitate positive transition outcomes for CLD youth with disabilities who come from families whose value systems differ from those of mainstream American society. Specifically we present a person-family interdependent approach to transition that emphasizes family empowerment, sustainability of transition services, and adaptations to the transition planning process.

CONCLUSION: In contrast and in comparison to the more traditional approach to transition that is currently practiced in American public schools, we believe that this person-family interdependent approach, if adopted, may result in better long term transition outcomes for CLD youth with disabilities as well as greater satisfaction of their families with the transition planning process.
\end{abstract}

Keywords: Cultural diversity, transition planning

\section{Introduction}

The Individuals with Disabilities Education Act of 2004 (IDEA 04) established transition services as a priority for all youth with disabilities beginning no later than the student's 16th birthday. Transition services are intended to help youth with disabilities make the transition from school to the world of adulthood by using a coordinated set of activities that are results oriented. The focus of these services is to improve the youth's academic and functional achievement and facilitate their movement from school to post-school

*Address for correspondence: Edwin O. Achola, Ph.D., Assistant Professor, California State University, Long Beach, 4465, Casa Grande Circle, Apt 143, Cypress, CA 90630, USA. Tel.: +1 724466 2988; Fax: +1 562985 4534; E-mail: Edwin.achola@ csulb.edu. activities in the areas of postsecondary education, employment, and if appropriate, independent living.

Despite the positive intent of IDEA 04 to improve the adult lives of youth with disabilities, historical data from the National Longitudinal Transition Study (NLTS-1) found that these individuals had poorer post-school outcomes than their non-disabled peers, particularly in the domains of employment and postsecondary education (Blackorby \& Wagner, 1996). Furthermore, NLTS-1 findings indicated that postsecondary outcomes for culturally and linguistically diverse (CLD) youth with disabilities, particularly those who had who had low socioeconomic status (SES), were even worse compared to peers from the dominant culture. A pattern of poorer postschool outcomes for ethnically diverse youth with 
disabilities has continued, as evidenced in recent data found in the NLTS-2 which indicated that low SES African American and Hispanic youth with disabilities had lower rates of high school graduation and college enrollment compared to their White peers with disabilities (Wagner, Newman, \& Javitz, 2014).

Transition planning is a key component of IDEA 04 and is intended to involve a youth with a disability and their family in identifying postsecondary goals along with adult services and supports to help achieve these goals. It has consistently been found that parents of CLD youth with disabilities and from low-income households tend to be less satisfied with their level of involvement in the transition planning process compared to parents from other backgrounds (Brandon \& Brown, 2004; Cameto, Levine, \& Wagner, 2004; Greene, 2011; Rueda et al., 2005), struggle to access community resources that are available to them (Cartledge, Gardner, \& Ford, 2008), and feel that their contributions to the transition planning process is under-valued by school professionals (Geenen, Powers, \& Lopez-Vasquez, 2001).

In a nation of immigrants where the minority is rapidly becoming the majority and poverty continues to be a challenge for many American families, it is imperative that transition services and outcomes for CLD youth with disabilities be improved. Despite years of research on culturally relevant pedagogy as it relates to learners with exceptionalities, there has been little agreement on specific evidence-based practices that meet the transition needs of CLD youth and other underrepresented populations. The purpose of this paper is two fold. First, we will review current knowledge about the experiences of CLD youth with disabilities and their families in the transition planning process, followed by a presentation of a new and different perspective on this topic. Second, we will propose a person-family interdependent approach that represents a more culturally responsive way to engage CLD youth with disabilities and their families in the transition process. We believe that adoption of this approach may result in significantly better post-school outcomes for CLD youth with disabilities in the future.

\section{Old and new perspectives}

A lack of meaningful involvement of CLD families in the transition planning process has been well documented in transition literature and has been suggested as a reason for the poorer post-school outcomes of
CLD youth with disabilities. A number of barriers experienced by CLD families engaged in transition planning have been identified. These include poor relationships between parents and educators (deFur et al., 2001; Geenen et al., 2005; Schuster, Timmons, \& Moloney, 2003; Shapiro et al., 2004; Zionts et al., 2003), intimidation experienced by CLD families when interacting with school personnel in public school settings (Landmark et al., 2013), CLD parents' lack of understanding of the transition planning process (Geenen et al., 2005; Landmark et al., 2007), and negative attitudes of professionals toward CLD children and a lack of training on cultural underpinnings of practice (McCall \& Skrtic, 2009). Further challenges CLD families experience are cultural differences such as ethnic, linguistic, socioeconomic, and lower parental educational achievement levels. Some professionals report that CLD families lack an understanding of the importance of transition planning as it relates to their child's future (Landmark et al., 2007). Finally, CLD parents have reported not being given ample opportunity by school personnel to participate in transition planning (Wagner et al., 2006).

Although limited involvement of CLD families in the transition planning process may be a factor related to the poorer post-school outcomes of CLD youth with disabilities, this explanation may be insufficient. There are other possible explanatory variables for the poorer post-school outcomes of CLD youth with disabilities that have not been adequately investigated in transition outcome studies of CLD youth with disabilities. One example of this is the inherent value differences between families who represent mainstream American culture compared to families who are culturally and linguistically different. Mainstream American values typically include individualism, upward mobility, personal choice, and self-determination and are derived from AngloEuropean cultures. Many CLD families place less emphasis on these types of values, subscribing to values that are often radically different from those espoused in the mainstream American culture. Moreover, values such as self-determination, individualism and personal choice manifest themselves differently in cultures that are more collectivistic in orientation. Thus, in order to accurately examine the transition outcomes and experiences of CLD youth with disabilities, it is critical for transition researchers to determine the extent to which CLD study participants endorse mainstream American values versus values that are considered culturally different. 
A second shortcoming of existing transition literature is the lack of representation of CLD youth with disabilities in subject samples. Grifin (2011) reviewed the demographic characteristics of participants in transition intervention studies and noted that very few CLD individuals were involved; the majority of participants $(65 \%)$ in these studies were Caucasian. When participants from diverse backgrounds are omitted or included in insufficient numbers, narrow findings are interpreted too broadly (Graham, 1992).

A third shortcoming in existing transition literature is the use of the term "CLD" which primarily focuses on youth with disabilities from the following groups: African Americans, Asian Americans and Pacific Islanders, Hispanic Americans, Native Americans, students who speak English as a second language, and students who have undocumented or immigrant status (Trainor et al., 2008). Inherent in this conceptualization of CLD is the assumption that race, immigration history, and linguistic background are the primary indicators of cultural diversity. While it is true that many racially and linguistically diverse individuals and recent immigrants are also culturally diverse (Kalyanpur \& Harry, 2013), defining cultural diversity in terms of categorical indicators such as race, ethnicity, immigration background, and language inadvertently reinforces the notion that cultural diversity is a static quality only true for some people. Many scholars argue that cultural diversity is a relational dynamic that exist between persons within specific contexts rather than a static quality. Barrera and Corso (2000), for example, reported that many people use the term cultural diversity to identify differences that are perceived to stem from culture without examining actual differences in behavior, values, and beliefs. It is therefore not surprising that existing transition literature has relied primarily on race and language to distinguish CLD families from the mainstream normative group when collecting data. In so doing, important differences in behavior and habits of mind brought about by differences in beliefs, acculturation patterns, and the extent of socialization may not have been properly accounted for in transition studies. This may be particularly problematic in instances where CLD individuals endorse both mainstream and nonmainstream values to varying degrees. It is important to note that aside from the influence of race and language, the cultural identity of any individual may reflect features of the macroculture, of one's original microculture, and of any other microcultural groups within society (Kalyanpur \& Harry, 2013). In short, the construct of cultural and linguistic diversity is much more complex than what is reflected in transition literature at the present time.

New and different perspectives on cultural and linguistic diversity need to be incorporated and explored in transition outcome studies of CLD youth with disabilities. One such perspective is the person-family interdependent approach to transition which is presented next. In contrast to the traditional approach to transition, we argue that the person-family interdependent approach is more suited to the unique characteristics and needs of CLD youth with disabilities and their families (see Table 1 for a comparison of these two approaches to transition).

\section{Person-family interdependent approach to transition}

A person-family interdependent approach to transition takes into account the close relationship between the quality of life of a CLD family and the future adult life of their child with a disability. For many CLD families, transition is not a discrete time in life affecting only their child with a disability. The family as a whole is affected by the transition process and potential adult outcomes of their child (Marshak, Seligman, \& Prezant, 1999; Szymanski, 1994). Evidence for this comes from a study by Rueda et al. (2005) who found that among Latino mothers of children with developmental disabilities, the future well-being of their child was not considered to be separable from the overall well-being of their family. The notion of independence in the Latino families who participated in this study was marked by shifts in specific roles that family members achieved during adulthood, such as when a child gets married, rather than simply reaching the age of adulthood (e.g., 18 years old).

Continued interdependence between family members, including the youth with a disability into adulthood, was expected and maintained.

The person-family interdependent approach to transition takes this into consideration and requires transition professionals to engage in a number of very specific practices. First, the transition IEP team should discuss the CLD young adults' current and future roles in supporting their family, as well as their expected roles within the broader cultural community. Transition goals for a CLD youth with a disability should be aligned with these cultural and 
Table 1

Comparisons between traditional approach and person-family centered approach to transition planning

\begin{tabular}{|c|c|c|}
\hline Domain & Traditional Service Plan & Person-Family Interdependent Plan \\
\hline Transition focus & Primary focus on youth outcomes & Addresses both student and family outcomes \\
\hline Sustainability & $\begin{array}{l}\text { Responsibility for transition services dependent } \\
\text { on professionals (school personnel, } \\
\text { administrators and agencies) }\end{array}$ & $\begin{array}{l}\text { Responsibility for transition services shared } \\
\text { between families, community members and } \\
\text { professionals }\end{array}$ \\
\hline \multirow[t]{3}{*}{ Sustainability Empowerment } & Limited or no involvement of extended Family & Extended family involved \\
\hline & $\begin{array}{l}\text { Links between families and post school agencies } \\
\text { developed }\end{array}$ & $\begin{array}{l}\text { Links between families and post school agencies } \\
\text { developed }\end{array}$ \\
\hline & Based on the deficit model & Based on family strengths \\
\hline Assessments & $\begin{array}{l}\text { Assessment do not include a review of family } \\
\text { cultural background }\end{array}$ & $\begin{array}{l}\text { Assessment include a review of family cultural } \\
\text { background }\end{array}$ \\
\hline \multirow[t]{5}{*}{ Assessments Transition Goals } & $\begin{array}{l}\text { Selection of instruments and interpretation of } \\
\text { results based on convenience }\end{array}$ & $\begin{array}{l}\text { Selection of instruments and interpretation of } \\
\text { results are guided by family background }\end{array}$ \\
\hline & Involves multiple individuals & Involves multiple individuals \\
\hline & Limited or no adaptations made & $\begin{array}{l}\text { Adaptations that reflect the sociocultural and } \\
\text { linguistic backgrounds of the family }\end{array}$ \\
\hline & Transition goals aligned with youth expectations & $\begin{array}{l}\text { Transition goals aligned with youth and family } \\
\text { expectations }\end{array}$ \\
\hline & $\begin{array}{l}\text { Goals determined by participants at the IEP } \\
\text { meeting }\end{array}$ & $\begin{array}{l}\text { Goal setting process considers decision making } \\
\text { structures in families }\end{array}$ \\
\hline \multirow[t]{3}{*}{ Measure of success } & Youth transition goals are met & Youth transition goals are met \\
\hline & & Family needs met \\
\hline & & Family satisfied \\
\hline
\end{tabular}

family interdependent expectations. An example of this can be found in research findings which indicated that many Asian Americans and Pacific Islanders continued to live at home with their family when they transitioned to adulthood, with relatively low rates of residing alone (Harris \& Jones, 2005; Reeves \& Benette, 2004). Similarly, it has been commonly found that young men from the Church of Latter Day Saints participated in two years of missionary work after high school in line with their faith obligations and family traditions rather than pursuing independent adult hopes and aspirations immediately after high school. Transition goals in both of these instances need to include opportunities for meeting family obligations in addition to skills necessary for future adult independent living.

Second, the transition IEP team must identify the relationships between proposed transition activities for the CLD youth with a disability and their family's needs, with the aim of developing transition goals and services that take the family's needs into consideration. For example, some transition plans include job-shadowing experiences that involve a student going to a workplace after school. Since some CLD youth are expected after school hours to help with duties at home such as baby-sitting in order to enable their parents to go to work, it is critical for the transition IEP team to ensure that job shadowing experiences do not extend beyond school hours. Similarly, many young people from low SES backgrounds have traditionally worked to contribute financial support to their families (Lerman, 2000). During the transition IEP meeting, a discussion about how income gained from the employment of a CLD youth with a disability can benefit their family may facilitate the family's understanding of the need to have an employment goal included on their child's individual transition plan (ITP). Likewise, being able to contribute to their family's financial well-being may motivate a CLD youth with a disability to seek adult paid competitive employment, thereby increasing their desire to have an employment goal included on their ITP.

Next, consider the important roles that typically extend into adulthood that youth from certain cultures play within their families and cultural communities (e.g., childcare, providing financial support, caring for in-laws and older relatives). Studies have shown that Asians (42\%) are more likely to assist in caring for or financially supporting parents, in-laws, or other older relatives than are Hispanics (34\%), Blacks (28\%), or Whites (19\%) (American Association of Retired Persons, 2003). Transition plans should take these roles into consideration by including transition goals for an Asian youth with a disability that reflect the adult roles expected by their family and cultural community.

Transition IEP team members must also give careful and non-judgmental consideration to a CLD family's beliefs and expectation about their young 
adults' future responsibilities based upon the child's gender, birth order, and disability. Despite the dramatic changes in gender roles that have occurred in the United States during recent decades, factors such as gender and birth order still influence family expectations of children in other cultures. For example, Raffaelli and Ontai (2004) found that gender role differentiation and privileging of boys in families with both sons and daughters were frequent among certain Latino families. In many cases, sons were typically granted more freedom than daughters. Also, daughters and sons tended to have different household responsibilities; in particular, girls were expected to help around the house, whereas boys were not. Similarly, Pyke (2005) found that among Vietnamese and Korean families, first-born and older siblings were likely to have been afforded higher status, were disciplinarians to younger siblings, and had more traditional viewpoints and behaviors closer to those of their parents and not their own generation in the family. Such hierarchical structures stand in contrast to Anglo-European family configurations in which factors such as birth order and gender have limited influence with regard to roles of individuals within a family.

In view of such variations, it is crucial for transition professionals to gather information from a number of sources, including parents, the child himself/herself, other family members, members of the cultural community, as well as siblings and school personnel who have observed the CLD family's interactions with one another. Transition professionals must exercise great caution while obtaining information about a CLD family to avoid bias, stereotyping, and negative perceptions regarding the family's values, attitudes, beliefs, social class, and level of education. Failure to do so can dramatically impede efforts to actively involve CLD families in the transition planning process.

Next we will discuss the importance of family empowerment in the transition planning process, including unique considerations when working with families who are from culturally different backgrounds.

\subsection{Culturally sensitive strengths-based family empowerment}

The aim of family empowerment is to reinforce a family's existing capacities, build on their strengths, and facilitate client-directed changes that are mean- ingful and significant (Carlson, Armitstead, Rodger, $\&$ Liddle, 2010). An important intent of the transition requirements of IDEA 04 was to increase family participation in the transition planning process. And yet a conundrum exists with the notion of family empowerment because it implies that someone "invests" someone else with power or authority to make decisions (Wehmeyer, 2004). Family empowerment models present in existing transition literature have tended to focus on strong parent motivation, skill development, and sharing of knowledge with families. For example, Turnbull et al. (2006) proposed an empowerment model that views families as empowered when they possess a high degree of motivation and have sufficient knowledge and skills when engaged in the transition planning process. We argue, however, that this conceptualization of family empowerment is one that is deeply enmeshed in the deficit orientation and emphasizes the macro cultural values of equity and participatory democracy often associated with the dominant culture in western societies. Models and approaches to family empowerment of this type may be inappropriate when applied to families who are culturally and linguistically diverse, particularly those who come from non-western societies.

With these thoughts in mind, transition IEP team members should recognize that although they may wish to actively encourage parity between professionals and CLD families in the transition planning process and foster positive and mutually beneficial relationships, many culturally diverse parents view professionals as authority figures to whom they should show deference. For example, Kalyanpur and Harry (2013, p. 68) commented that "any effort on the part of a CLD parent to place themselves on an equal footing with a professional would likely smack of extreme conceit and disrespect." This can subsequently result in a further constraint in the parent professional relationship.

A culturally sensitive approach to parental empowerment demands a willingness among transition professionals to acknowledge and accept that some CLD families are more comfortable with hierarchical versus equal relationships between professionals and parents. In such instances, it is possible that a CLD family may believe that their contributions will be disregarded or considered inappropriate by transition professionals, resulting in the family being reluctant to participate in the transition process. A simple way to explore this with a CLD family would be to ask them about their perceptions, role expectations, and 
perceived responsibilities prior to engaging them in transition planning.

The ultimate goal of the person-family interdependent perspective is to facilitate reciprocal skill building and knowledge sharing between professionals and families and thereby maximize the comfort level of a CLD family. Reciprocity in this context implies acknowledging and trusting that everyone involved in the collaborative process has valuable experiences to share and can make contributions that are of equal value (Barrera \& Corso, 2003). Transition professionals who engage in such cultural reciprocity seek to build their skills and knowledge by listening to CLD families in a meaningful way. This type of listening requires transition professionals to temporarily suspend culturally bias judgments and avoid defending their position. The knowledge gained from listening to CLD families can subsequently be used by transition professionals to facilitate more productive engagement of CLD families in the transition planning process. An example of this would be a transition IEP team that uses culturally relevant information shared by a CLD family to discuss problem-solving strategies to help determine culturally relevant transition goals for a CLD with a disability. One such strategy that might be useful when working with parents from cultures that practice hierarchical decision-making would be to suggest to the parent who is lower on the family hierarchy that they discuss and agree upon transition goals with their partner prior to attending the IEP meeting and signing the transition portion of the IEP.

\subsection{Sustainable transition planning}

Sustainable transition planning goes beyond focusing on short-term student transition outcomes, focusing instead on the creation of lasting outcomes. Such long term transition outcomes include completion of post-secondary education, upward mobility in selected careers, and satisfactory adult living. Sustainable transition planning takes into consideration the fact that youth with disabilities tend to move from one transition service system to another over time as they enter and progress through adulthood. For this reason, transition services and supports for a young adult with a disability must be sustainable over time. Studies have shown that successful transition outcomes are more likely for youth with disabilities who have support and services available to them that extend beyond secondary school (Benz, Lindstorm, \& Yovanoff, 2000). Transition experts have indicated that potential obstacles to a seamless transition process are lessened when youth with disabilities connect with agency representatives such as rehabilitation professionals before high school completion and are provided uninterrupted transition services after they exit school (Agran, Cain, \& Calvin, 2002).

Sustainable transition planning requires professionals to operate on several important assumptions. First, special education professionals must acknowledge that the family is a constant in the life of a youth with a disability. Youth with disabilities often transition across multiple service systems as a consequence of eligibility requirements that begin and end at various points in their lifetimes. As young adults with disabilities transition between various transition service agencies and systems, their families often continue to be involved in their lives while certain transition professionals conclude their contacts with them. For example, once a youth with a disability exits high school, either by graduating with a diploma at age 18 or obtaining a certificate of completion at age 22 , they no longer remain in contact with school transition personnel. Adult transition services such as Vocational Rehabilitation or Disability Support Services at colleges typically take over the role of helping facilitate positive adult outcomes for the young adult with a disability. It is important for transition IEP team members to connect families with adult transition service providers from whom youth with disabilities anticipate receiving services after high school. In fact, IDEA 04 transition regulations require this, thereby supporting the notion of sustainable transition planning.

Several unique characteristics of families from various cultures should be taken into consideration when attempting to promote sustainable transition planning for CLD youth with disabilities. Transition professionals need to be aware of the critical roles played by extended family, friends, and important cultural community members (e.g., faith community leaders) in the transition planning process. Many culturally diverse families to a great degree subscribe to values such as collectivism, familism, family obligation, and relational orientation; the common thread uniting these values is the theme of family interdependence (Yee et al., 2007). Familism values a set of normative beliefs that emphasize the centrality of the family unit and stresses the obligations and support that family members owe to both nuclear and extended kin (Sabogal et al., 1987). Carlo, Koller, Raffaelli, and Guzman (2007) pointed out that this type of 
familial interdependence and collective orientation in culturally diverse families serves as a strength by promoting family characteristics that are adaptive and which enhance optimal success for individuals within many culturally diverse societies.

Transition professionals working with CLD families should determine the degree to which they embrace family interdependent values. CLD families who ascribe to such values will be able to identify other family members who can provide useful input and information for developing and creating transition services for a CLD youth with a disability. For example, a transition IEP team may choose to pair a CLD youth with a disability with an older cousin who is already enrolled in college to help explore and understand the admission process as well as the social aspects of participating in post-secondary education. Similarly, a CLD youth with a disability may feel more comfortable being placed in a job shadowing employment setting with a family friend or a respected leader in the faith community who is involved in a career path of interest. Transition services of these types open up avenues for CLD family strengths to be utilized as the framework upon which transition supports and services can be provided to a CLD youth with a disability. Additionally, since family-based transition services are often not dependent on public funding or school personnel, they have the advantage of continuing beyond high school and being sustainable through adulthood for a CLD youth with a disability.

Another unique characteristic of families from different cultures that can be utilized to promote sustainable transition planning is the existence of family-to-family networks. Transition IEP teams frequently rely on public services, agencies, and resources when engaged in transition planning for youth with disabilities (Levine \& Wagner, 2004). For many culturally diverse families, having to rely on such resources may restrict the range of opportunities available to their child with a disability. Moreover, it has been found that for many culturally diverse families, soliciting support from others in their cultural community is significantly more comfortable than consulting with school professionals (Van Haren $\&$ Fielder, 2008). Family-to-family networks provide time and opportunity for CLD families to connect, learn from, and support one another during the transition years of their sons/daughters with disabilities. In addition, this type of networking increases the likelihood that CLD families will develop the social and cultural capital necessary for success when they are linked with other families who are more familiar with the dominant culture. Support for this statement comes from Trainor (2008), who indicated that sound transition planning and instructional practices require careful consideration of the cultural and social capital that adolescents with disabilities bring to the transition process. Family-to-family networks allow for the creation, acquisition, and use of capital during transition into adulthood thereby providing sociocultural information regarding services for youth with disabilities. This type of information is essential for addressing the various multicultural issues and challenges present in today's special education environment (August \& Hakuta, 1998).

\subsection{Family-centered adaptation of transition practices}

Some school practices, while designed to address student and family needs, have the potential to alienate their intended audience because they represent attitudes and practices that families from particular cultures may not embrace (Harry, Kalyanpur, \& Day, 1999; Rueda et al., 2005). Two such examples considered best practices in transition planning are person-centered planning and student lead IEPs. Despite an abundance of evidence supporting these practices, both focus almost exclusively on promoting the quality of life of the individual with the disability rather than emphasizing their overall family's quality of life (Kim \& Turnbul, 2005). As noted earlier, transition is not a discrete time in life affecting only the individual with the disability; their family as a whole is often affected by the transition process and outcomes achieved by their young adult with a disability (Marshak, Seligman, \& Prezant, 1999; Szymanski, 1994).

Adoption of a person-family interdependent approach to transition planning with CLD families can be facilitated by making culturally relevant adaptations in the transition assessment and transition goal setting processes. Although these two components of transition planning are not the only ones that should be adapted, they do represent adaptations that can easily be implement by transition professionals who practice the person-family interdependent approach. A discussion of these two recommended adaptations is presented next.

\subsubsection{Adaptations to transition assessments}

Transition assessment allows teachers, families, and agencies to determine a student's postsecondary 
strengths, interests, preferences, and needs (Mazzotti et al., 2009). Transition assessment is a key mandate contained in the transition requirements of IDEA 04. Transition assessment data can be used for developing transition goals and services in the transition portion of an IEP for a youth with a disability (Sitlington, Neubert, \& Leconte, 1997).

Despite an extensive discussion in special education literature of culturally biased educational assessment practices (Carrasquillo, 1991; Macswan \& Rolstad, 2006), little attention has been paid to the topic of culturally biased transition assessment. In fact, only one study has been published on this topic since transition planning was first mandated by federal legislation in 1990. In this review, Dais (1993) asserted that minorities suffer as a result of traditional assessment practices which have proven to be inaccurate and inconsistent, yet continue to be used in prediction, decision-making, and inferences about student performance and lifelong success.

Transition professionals need to be cognizant of the limited information and resources available for conducting culturally relevant transition assessments with CLD youth with disabilities. There are a number of recommendations that school transition personnel should consider when selecting, administering, and interpreting transition assessments for this unique population of individuals with disabilities.

1. Conduct a review of all available historical and background information about the CLD student and their family to facilitate the selection of appropriate transition assessment instruments and the interpretation of assessment results. For example, the Self-Determination Scale (Wolman et al., 1994) parent form requires parents to answer the question, "At home, people understand my child when (s)he has to change plans to meet his or her own goals. They offer advice and encouragement." Hypothetically, a CLD parent of a youth with a disability may not respond to this question, not because of an inability to comprehend the question but because of family beliefs and values that lie outside the boundaries of the normative culture. An accurate interpretation by transition professionals of a lack of response to the question by a CLD family is heavily dependent on the professional's knowledge of the family's cultural background and beliefs.

2. Involve multiple individuals in the transition assessment process. It is not uncommon for professionals to use information from a single transition assessment administered only to the young adult with a disability, perhaps due to time constraints. Many scholars agree that a quality comprehensive transition assessment involves gaining the perspectives of multiple individuals who know a student well and/or who are familiar with the expectations of the current or future environments in which a student will participate (Carter et al., 2009; Karan, DonAroma, Bruder, \& Roberts, 2010). This practice allows the sharing of different perspectives and expectations regarding what should be addressed in a student's transition plan and supports needed to facilitate the individual's successful transition to adult life (Carter, Brock \& Trainor, 2014).

3. It is equally important to consider transition assessment adaptations that reflect the sociocultural and linguistic backgrounds of the family. For example, when working with CLD families that are organized hierarchically, transition professionals should identify and engage the designated or assumed decision maker in the family during the transition assessment process. This is especially true with regard to some Asian American parents, who have been described as more hierarchical and less democratic compared to parents from Caucasian families (Chao \& Tseng, 2002).

\subsubsection{Adaptations for goal setting}

One key component of the transition planning process is goal setting. IDEA 04 requires ITPs to contain appropriate measurable postsecondary goals that are annually up-dated and based upon age appropriate transition assessment, including annual goals relevant to the student's transition services needs (Mazzotti et al., 2009). Further, the law requires IEP teams to develop goals in the transition domains of postsecondary education, employment and, if necessary, independent living (Kohler \& Field, 2003).

Current research has characterized transition goals as vague and overly broad, suggesting limited connections between young adults' unique characteristics and the post school goals identified in their transition plans (Powers et al., 2005; Trainor, 2005b). Moreover, disparities in transition goals have been identified across different ethnic groups. Trainor (2005b) found that transition goals designating postsecondary education participation were included with higher frequency on the ITPs of Caucasian Americans 
compared to the ITPs of their African American and Latino peers. This disparity in ITP goals may be partially explained by lower expectations in school professionals of minority youth with disabilities. Evidence shows, however, that such lower expectations are rarely shared by many CLD families. For example, many children of immigrants generally share their parents' belief that education is a path to future adult life success, thereby motivating first and second generation CLD youth to work especially hard, even in the face of obstacles such as low English proficiency, poverty or substandard schooling (Yee et al., 2007). For this reason, it is incumbent upon transition professionals to align their expectations more closely with those of CLD families, particularly in instances where the families embrace such high expectations for their children. In addition, transition goals for CLD youth with disabilities should be discussed within the context of the CLD family's goals. Empirical literature suggests that many CLD families play a significant role in helping young adults choose career pathways. For instance, many immigrant families have perceptions about which occupations will more effectively ensure long term economic family security and strongly encourage pursuit of these occupational careers by younger family members (Castelino, 2005). Transition IEP teams should take these perceptions and desires into consideration when developing ITP goals for CLD youth with disabilities in the areas of postsecondary education/training and employment.

\section{Conclusion}

Scholars addressing transition outcomes of CLD youth with disabilities have argued that existing knowledge in special education has yet to assemble robust evidence-based practices to address the strengths and needs of this unique population in U.S. schools (Artiles et al., 2010). Some authors have endorsed family-centered practices as a means for increasing positive outcomes for CLD youth with disabilities (Dunst \& Trivette, 2005; King et al., 1999). In contrast, others have argued for more traditional child-centered practices such as person-centered transition planning (Callicot, 2003; Hasnain \& Sotnik, 2003). In fact, there are some commonalities between these two distinct approaches to transition planning. For example, both familycentered and person-centered approaches advocate the inclusion of individuals most involved in a child's life in the transition planning process. Moreover, both strategies represent decentralized consumerbased planning designed to shift the philosophical and practical responsibility for planning transition services from human service professionals to people with disabilities and their families. However, the two planning methods differ in important ways. Specifically, child-centered plans put greater emphasis on meeting the transition needs of the individual youth with a disability and encourage future adult independence from his/her family. Family-centered plans, on the other hand, encourage planners to pursue transition goals within parameters set by the family and encourage family interdependence. Within each of these strategies, there is an opportunity for the inclusion of values shared by both mainstream and non-mainstream communities. We recommend that transition service providers move toward an interdependent model that merges the two approaches so as to create more culturally responsive transition practices. We believe that adoption of this approach will lead to better post school outcomes for CLD youth with disabilities in the future and greater satisfaction with the transition planning process within their families. A second recommendation is that empirical data be gathered on the use of culturally responsive transition practices to determine the validity of their effectiveness for improving the transition planning process for CLD youth with disabilities and their families. To date, empirical-based studies of this nature are lacking in the field, a situation which deserves greater attention by scholars interested in improving the practice of culturally responsive transition planning.

\section{Conflict of interest}

The authors have no conflict of interest to report.

\section{References}

American Association of Retired Persons (AARP). (2001). In the middle: A report on multicultural boomers coping with family and aging issues. Relations. Retrieved from http://www.aarp.org/research/housing-mobility/caregiving/ aresearch-import-789-D 17446.html

Agran, M., Cain, H. M., \& Cavin, M. D. (2002). Enhancing the involvement of rehabilitation counselors in the transition process. Career Development for Exceptional Individuals, 25, 141-155.

August, D., \& Hakuta, K. (1998). Education language-minority children. Washington, DC: National Academy Press. 
Artiles, A. J., Kozleski, E. B., Trent, S. C., Osher, D., \& Ortiz, A. A. (2010). Justifying and explaining disproportionality, 1968-2008: A critique of underlying views of culture. Exceptional Children, 76, 279-290.

Barrera, I., \& Corso, R. M. (2000). Skilled dialogue: Strategies for responding to cultural diversity in early childhood. Baltimore, MD: Paul H. Brookes.

Benz, M. R., Lindstrom, L., \& Yovanoff, P. (2000). Improving graduation and employment outcomes of students with disabilities: Predictive factors and student perspectives. Exceptional Children, 66, 509-541.

Blackorby, J., \& Wagner, M. (1996). Longitudinal post-school outcomes of youth with disabilities: Findings from the National Longitudinal Transition Study. Exceptional Children, 62(5), 399-413.

Cameto, R., Levine, P., \& Wagner, M. (2004) Transition planning for students with disabilities. Menlo Park, CA. SRI International. Retrieved from http://www.nlts2.org/ reports/2004_11/index.html.

Callicot, K. J. (2003). Culturally sensitive collaboration within person-centered planning. Focus on Autism and Other Developmental Disabilities, 18(1), 60-68.

Carlson, G., Armitstead, C., Rodger, S., \& Liddle, G. (2010). Parents' experiences of the provision of community-based family support and therapy services utilizing the strengths approach and natural learning environments. Journal of Applied Research in Intellectual Disabilities, 23, 560-572.

Cartledge, G., Gardner, R., \& Ford, D. Y. (2009). Diverse learners with exceptionalities: Culturally responsive teaching in the inclusive classroom. Merrill/Pearson Education.

Carlo, G., Koller, S., Raffaelli, M., \& de Guzman, M. R. T. (2007). Culture-related strengths among Latin American families: A case study of Brazil. Marriage and Family Review, 41, 335-360.

Carrasquillo, A. L. (1991). Hispanic children and youth in the United States: A resource guide. New York, NY: Garland.

Carter, E. W., Owens, L., Trainor, A. A., Sun, Y., \& Swedeen, B. (2009). Self-determination skills and opportunities of adolescents with severe disabilities. American Journal on Intellectual and Developmental Disabilities, 114, 179-192.

Carter, E. W., Brock, M., \& Trainor, A. A. (2014). Transition assessment and planning for youth with severe intellectual and developmental disabilities. The Journal of Special Education, 47, 245-255. doi: 101177/0022466912456241

Castelino, P. (2005). Factors influencing career choices of South Asian Americans: A path analysis. Dissertation Abstracts International, 65(8A), 2906.

Chao, R. \& Tseng, V. (2002). Parenting of Asians. In M. H. Bornstein (Ed.), Handbook of parenting: Vol. 4 Social conditions and applied parenting (2nd ed., pp. 59-93). Mahwah, New Jersey: Lawrence Erlbaum Associates.

Dais, T. A. (1993). An analysis of transition assessment practices. Do they recognize cultural differences? Chronic Illness, and Job Matching 2, 2-21

Dunst, C. J. \& Trivette, C. M. (2005) Characteristics and consequences of family- centered help giving practices. CASE makers, 1, 6, 1-4. Retrieved from http://www.fippcase.org/ casemakers/casemakers_vol1_no6.pdf.

Geenen, S., Powers, L. E., \& Lopez-Vasquez, A. (2001). Multicultural aspects of parent involvement in transition planning. Exceptional Children, 67, 265-282.

Graham, S. (1992). Most of the subjects were White and middle class: Trends in published research on African Americans in selected APA journals, 1970-1989. American Psychologist, 47, 629-639.

Griffin, M. M. (2011). Promoting IEP participation: Effects of interventions, considerations for CLD students. Career Development for Exceptional Individuals, 34, 153-164. doi: $10.1177 / 0885728811410561$

Harris, P. M., \& Jones, N. A. (2005). We the people: Performance Pacific Islanders in the United States (Census 20001244-1257. Special Report No. CENSR-26). Washington, DC: U.S. Census Bureau.

Harry, B., Kalyanpur, M. \& Day, M. (1999). The posture of cultural reciprocity: A practical approach to collaborative relationships with families from culturally diverse backgrounds. Baltimore, MD: Paul H. Brookes.

Hasnain, R., \& Sotnick, P. (2003). Person-centered planning: A gateway to improving vocational rehabilitation services for culturally diverse people, with disabilities. Journal of Rehabilitation, 69, 10-18.

Kalyanpur, M., \& Harry, B. (2012). Cultural reciprocity in special education: Building family-professional relationships. Baltimore, MD: Paul H. Brookes Publishing

Karan, O. C., Don, A., Bruder, M. B., \& Roberts, L. (2010) Transitional assessment model for students with severe and/or multiple disabilities. Intellectual and Developmental Disabilities, 48(5), 387-392

Kim, K., \& Turnbull, A. (2005). Transition to adulthood for students with severe intellectual disabilities: Shifting toward person-family interdependent planning. Research and Practice for Persons with Severe Disabilities, 29, 53-57.

King, G., King, S., Rosenbaum, P. \& Goffin, R. (1999). Familycentered caregiving and well-being of parents of children with disabilities: Linking process with outcome. Journal of Pediatric Psychology, 24, 41-53.

Kohler, P. D., \& Field, S. (2003). Transition-focused education: Foundation for the future. Journal of Special Education, 37, 174-183.

Landmark, L. J., Ju, S., \& Zhang, D. (2010). Substantiated best practices in transition: Fifteen plus years later. Career Development and Transition for Exceptional Individuals, 33(3), 165-176.

Landmark, L. J., Zhang, D. D., \& Montoya, L. (2007).Culturally diverse parents' experiences in their children's transition: Knowledge and involvement. Career Development for Exceptional Individuals, 30(2), 68-79.

Lerman, R. (2000). Are teens in low-income and welfare families working too much? Washington, DC: The Urban Institute.

Levine, P., Marder, C., \& Wagner, M. (2004). Services and supports for secondary school students with disabilities: A special topic report of findings from the National Longitudinal Transition Study-2 (NLTS2). Menlo Park, CA: SRI International

Marshak, L., Prezant, F., Dandenau, C., \& L'Amoreaux, N. A. (2009). The school counselor's guide to effectively helping students with disabilities: Practicalities and possibilities. San Francisco, CA: Jossey Bass

Macswan, J., \& Rolstad, K. (2006). How language proficiency tests mislead us about ability: Implications for English language learner placement in special education. Teachers College Record, 108, 2304-2328.

Marshak, L. E., Seligman, M., \& Prezant, F. (1999). Disability and the family life cycle. New York, NY: Basic Books.

Mazzotti, V. L., Rowe, D. R., Kelley, K. R., Test, D. W, Fowler, C. H., Kohler, P. D., \& Kortering, L. J. (2009). Linking transi- 
tion assessment and post-secondary goals: Key elements in the secondary transition planning process. Teaching Exceptional Children, 42(2), 44-51.

McCall, Z., \& Skrtic, T. M. (2009). Intersectional needs politics: A policy frame for the wicked problem of disproportionality. Multiple Voices for Ethnically Diverse Exceptional Learners, 11(2), 3-23.

Ortiz, A. A., \& Yates, J. R. (2010). Enhancing scientifically-based research for culturally and linguistically diverse learners. Multiple Voices, 11, 13-23.

Powers, L., Balandran, J., \& Palmer, C. (2005). Mandates and effective transition planning practices reflected in IEPs. Career Development for Exceptional Individuals, 28, 47-59.

Pyke, K. (2005). Generational deserters and black sheep: Acculturative differences among siblings in Asian immigrant families. Journal of Family Issues, 26(4), 491-517. doi: $10.1177 / 0192513$ X04273578

Raffaelli M., \& Ontai L. (2004). Gender socialization in Latino/a families: Results from two retrospective studies. Sex Roles.50:287-899. doi:10.1023/B:SERS.0000018886. 58945.06.

Reeves, T. J., \& Bennett, C. E. (2004). We the people: Performance. Pacific Islanders in the United States (Census 20001244-1257. Special Report No. CENSR-26). Washington, DC: U.S. Census Bureau

Rueda, R., Monzo, L., Shapiro, J., Gomez, J., \& Blacher, J. (2005). Cultural models of transition: Latina mothers of young adults with developmental disabilities. Exceptional Children, $71,401-414$.

Sabogal, F., Marin, G., Otero-Sabogal, R., Marin, B. V., \& PerezStable, E. (1987). Hispanic familism and acculturation: What changes and what doesn't? Hispanic Journal of Behavioral Sciences, 9, 397-412.

Shapiro, J., Monzo, L. D., Rueda, R., Gomez, J., \& Blacher, J. (2004). Alienated advocacy: Perspectives of Latina mothers of young adult children with developmental disabilities on service delivery systems. Mental Retardation, 42, 37-54.

Schuster, J. L., Timmons, J. C., \& Moloney, M. (2003) Barriers to successful transition for young adults who receive SSI and their families. Career Development for Exceptional Individuals, 26, 47-66.

Sitlington, P. L., Neubert, D. A., \& Leconte, P. J. (1997). Transition assessment: The position of the Division on Career Development and Transition. Career Development for Exceptional Individuals, 20, 69-79.
Szymanski, E. (1994). Transition: Life-span and life-space considerations for empowerment. Exceptional Children, 60(5), 402-410.

Trainor, A. A. Lindstrom, L., Simon-Burroughs, M., Martin, J. E., \& Sorrells, A. (2008). From marginalized to maximized opportunities for diverse youths with disabilities: A position paper of the division on career development and transition. Career Development for Exceptional Individuals, 31, 56-64. doi: $10.1177 / 088572880731777$

Trainor, A. A. (2008). Using cultural and social capital to improve postsecondary outcomes and expand transition models for youth with disabilities. Journal of Special Education, 42, 148162.

Trainor, A. A. (2005). To what extent are transition components of individualized education programs for diverse students with learning disabilities culturally responsive? Multiple Voices, 8 , 111-127.

Turnbull, A., Turnbull, R., Erwin, E., \& Soodak, L. (2006). Families, professionals, and exceptionality: Positive outcomes through partnerships and trust (5th ed.), Upper Saddle River, NJ: Merrill/Prentice Hall.

Van Haren, B., \& Fiedler, C. R. (2008). Support and empower families of children with disabilities. Intervention in School \& Clinic, 43(4), 231-235.

Wagner, M. M., Newman, L. A., \& Javitz, H. S. (2014). The influence of family socioeconomic status on the post-high-school outcomes of youth with disabilities. Career Development and Transition for Exceptional Individuals, 37, 5-17.

Wehmeyer, M. L. (2004). Self-determination and the empowerment of people with disabilities. American Rehabilitation, 28, 22-29.

Wolman, J. M., Campeau, P. L., DuBois, P. A., Mithaug, D. E., \& Stolarski, V. S. (1994). AIR Self-Determination Scale and User Guide. Washington, DC: American Institutes for Research.

Yee, B. W. K., DeBaryshe, B. D., Yuen, S., Kim, S., \& McCubbin, H. (2007). American and Pacific Islander families. In F. Leong, A. G. Inman, A. Ebreo, L. Yang, L.M. Kinoshita, \& M. Fu (Eds.), Handbook of Asian American psychology (2nd ed.) (pp.69-86). Thousand Oaks, CA: Sage.

Zionts, L., Zionts, P., Harrison, S., \& Bellinger, O. (2003). Urban African American families' perceptions of cultural sensitivity within the special education system. Focus on Autism and Other Developmental Disabilities, 18(1), 4. 